\title{
Challenging Behaviours among Children with Autism
}

\author{
S.Saradha Priyadarshini ${ }^{1}$, Dr. S. Thangarajathi ${ }^{2}$
}

Keywords: Behaviours, Children, Autism

Children are very social creatures who need and want contact with others to thrive and grow. They smile, cuddle, laugh, and respond eagerly to games like "peek-a-boo" or hide-and-seek. Occasionally, a child does not interact in this expected manner. Instead, the child seems to exist in his or her own world, a place characterized by repetitive routines, odd and peculiar behaviours, problems in communication, and a total lack of social awareness or interest in others. These are characteristics of a developmental disorder called autism.

Autism is a complex developmental disability that typically appears during the first three years of life and is the result of a neurological disorder that affects the normal functioning of the brain, impacting development in the areas of social interaction and communication skills. Children with autism will have difficulty in understanding and reacting to the world around them. Parents can easily identify the condition in the early years of child's life by noticing the characteristics present in them. Some of the common characteristics are as follows

1. Impaired social relationships

2. Communication and language deficits

3. Unusual responsiveness to sensory stimuli

4. Insistence on sameness and preservation

5. Ritualistic and unusual behaviour patterns

6. Behaviour problems

Among all these challenging behaviours are the most challenging and stressful issues faced by the parents.

\section{CHALLENGING BEHAVIOURS AMONG CHILDREN WITH AUTISM}

Children with autism will express unwanted behaviour often and is not easily managed. Some of the behaviours identified by Aman \& et.al (1996) are

${ }^{1} \mathrm{Ph} . \mathrm{D}$ Scholar, Department of Educational Technology, Bharathiar University, Coimbatore-46

${ }^{2}$ Assistant Professor, Department of Educational Technology, Bharathiar University, Coimbatore-46

(C) 2015 I S priyadarshini, S. Thangarajathi; licensee IJIP. This is an Open Access Research distributed under the terms of the Creative Commons Attribution License (http://creativecommons.org/licenses/by/2.0), which permits unrestricted use, distribution, and reproduction in any Medium, provided the original work is properly cited. 


\section{Challenging Behaviours among Children with Autism}

\section{Conduct problem}

The term conduct problem refers to identifiable behaviours in the individual that fail to conform to societal norms and encroach on the rights of others. Some examples include oppositional and defiant behaviours and antisocial activities like lying, stealing, running away and physical violence.

\section{Insecure}

It is the state of being anxious or afraid

3. Anxiousness

It is characterized by extreme uneasiness of mind or brooding fear about some contingency

\section{Hyperactivity}

Hyperactivity is a physical state in which a person is abnormally active.

\section{Self-injury}

Self-harm behaviour includes any deliberate attempt to harm or destroy body tissue.

Examples of self-harming behaviours include cutting, burning, head-banging, and severe scratching.

\section{Stereotypic behaviour}

A stereotypic behaviour is a repetitive or ritualistic movement, posture, or utterance. Stereotypes may be simple movements such as body rocking, or complex, such as selfcaressing, crossing and uncrossing of legs, and marching in place

\section{Self isolation}

Social isolation refers to a complete or near complete lack of contact with society for members of social species

\section{Ritualistic behaviour}

Ritualistic behaviour is basically a pattern of behaviour that someone follows without realizing they are doing so. Examples of common ritualistic behaviours are continual hand washing, hoarding of unneeded items, and bizarre mannerisms.

\section{Irritable}

Irritability is an excessive response to stimuli. The term is used for both the physiological reaction to stimuli and for the pathological, abnormal or excessive sensitivity to stimuli. It is usually used to refer to anger or frustration.

Finally these challenging behaviours become barriers to effective social and educational development (Horner et al, 2000 \& Riechle, 1990). It will also hinder the activities of children in the classroom environment and produces a challenging task for teachers to manage them. Those behaviours in turn will put the young children at risk for exclusion and isolation from social, educational, family, and community activities (Sprague and Rian, 1993). 


\section{CAUSE FOR THE PROBLEM BEHAVIOURS}

Problem behaviour among children occurs due to a variety of causes and is noted in various situations. Some of the major causes of the behaviour problems are as follows.

\section{Sensory issues}

Children with autism are overwhelmed by sensory stimuli which fail them to effectively process the information from the outside world and assimilate in their brains. A decreased ability to process information leads to increased self stimulating behaviours.

\section{Social triggers}

Children with autism will not be interested in interacting with other people. He will be isolated being in his own world engaging in repetitive and unwanted behaviours.

\section{Communication problems}

Child will get frustrated if he is not able to communicate. The cause might be due to bad reflux that's hurting his throat, or he might be non verbal child. Eg: A child who is non verbal will not be able to express his needs and that time he will try to exhibit his needs through certain kinds of unwanted behaviours like screaming, crying, hitting self, and kicking etc.

\section{Interests}

The child might be inattentive in the classroom because he is not interested in that particular activity.

\section{NEED FOR THE STUDY}

It is vital to know the common behaviour problems present among children with autism so that necessary intervention strategies can be designed and implemented to overcome it. Thus the present study has made an attempt to identify the challenging behaviours among children with autism.

\section{OBJECTIVES OF THE STUDY}

1. To find out the significant difference, if any in the challenging behaviours present among male and female children with autism

2. To find out the significant difference, if any in the challenging behaviours present among children with autism belonging to different age group

3. To find out the significant difference, if any in the challenging behaviours present among verbal and non verbal children with autism

\section{HYPOTHESIS OF THE STUDY}

1. There is no significant differences in the challenging behaviours present among male and female children with autism

2. There is no significant differences in the challenging behaviours present among children with autism belonging to different age group 
3. There is no significant differences in the challenging behaviours present among verbal and non verbal children with autism

\section{METHOD OF STUDY}

Descriptive Survey method was adopted for the present study

\section{POPULATION AND SAMPLING}

Children with autism were considered as the population for the present study. The sample included 30 children with autism selected randomly from a special school located at Coimbatore city.

\section{TOOLS OF THE STUDY}

- The Nisonger Child Behaviour Rating Form - Teacher Version developed by Aman \& et.al. (1996) was used to identify the challenging behaviours among children with autism.

- The personal information sheet was also used in order to obtain background information of the sample.

\section{STATISTICAL TECHNIQUES}

1. Percentage

2. Mean

3. Standard deviation

4. $\mathrm{t}$ Test

5. Anova

\section{ANALYSIS AND INTERPRETATION}

1. Challenging Behaviours Faced By Children With Autism With Respect To Their Gender

Table 1: Mean SD and $F$ value for challenging behaviours with respect to their gender.

\begin{tabular}{|c|c|c|c|c|c|}
\hline Variables & Groups & N & Mean & SD & t/F Value \\
\hline \multirow{2}{*}{ Gender } & Male & 23 & 34.91 & 15.574 & 1.871 \\
\cline { 2 - 5 } & Female & 7 & 37.43 & 20.272 & (NS) \\
\hline
\end{tabular}

*Significant at 0.05 level

NS - Not significant at 0.05 level

The above table reflects the influence of gender in challenging behaviours of children with autism. It is depicted that the calculated' $t$ ' value (1.871) is lesser than the table value and is not significant at 0.05 level. Hence the hypothesis "There is no significant differences in the challenging behaviours present among male and female children with autism" is accepted. Therefore it can be concluded that the gender does not influence the challenging behaviours of children with autism 
2. Challenging Behaviours Faced By Children With Autism With Respect To their age. Table 2: Mean, SD and $F$ value for challenging behaviours with respect to age group.

\begin{tabular}{|c|c|c|c|c|c|}
\hline Variables & Groups & N & Mean & SD & t/F Value \\
\hline \multirow{3}{*}{ Age } & 5 years \& below & 4 & 20.25 & 7.719 & \multirow{3}{*}{$2.566^{*}$} \\
\cline { 2 - 5 } & 6-10 yrs & 17 & 35.94 & 14.973 & \\
\cline { 2 - 5 } & above 10 yrs & 9 & 41.44 & 18.769 & \\
\hline
\end{tabular}

*Significant at 0.05 level

NS - Not significant at 0.05 level

The table (2) presents the influence of age on challenging behaviours of children with autism. It is revealed that the calculated ' $t$ ' value (2.566) is higher than the table value and is significant at 0.01 level. Thus the stated hypothesis "There is no significant differences in the challenging behaviours present among children with autism belonging to different age group" is rejected. Further the mean value shows that the students belonging to the age group 6-10 years possess more challenging behaviours than others. Therefore it is reflected that the age exert a great influence upon the challenging behaviours of children with autism.

Table 3: Mean, SD and F value for challenging behaviours with respect to mode of communication.

\begin{tabular}{|c|c|c|c|c|c|}
\hline Variables & Groups & N & Mean & SD & t/F Value \\
\hline $\begin{array}{c}\text { Communication } \\
\text { mode }\end{array}$ & verbal & 16 & 41.31 & 15.882 & \multirow{2}{*}{$2.213^{*}$} \\
\cline { 2 - 5 } & Non verbal & 14 & 28.86 & 14.920 & \multirow{2}{|c}{} \\
\hline
\end{tabular}

* Significant at 0.05 level

NS - Not significant at 0.05 level

This table reflects the influence of mode of communication upon the challenging behaviours faced by children with autism. It is revealed from the table that the calculated ' $t$ ' value (2.213) is higher than the table value and is significant at 0.01 level. Further the mean value reveals that the more challenging behaviours are present among children with verbal communication. Hence the stated hypothesis "There is no significant differences in the challenging behaviours present among verbal and non verbal children with autism" is rejected.

\section{MAJOR FINDINGS AND INTERPRETATIONS}

1. There is no significant difference in the challenging behaviours present among male and female children with autism

2. There exist significant differences in the challenging behaviours present among children with autism belonging to different age group.

3. Students belonging to the age group 6-10 years possess more challenging behaviours than other children.

4. There is significant differences in the challenging behaviours present among verbal and non verbal children with autism

5. Children with verbal communication are facing more challenging behaviours than that of the non verbal 


\section{RECOMMENDATIONS OF THE STUDY}

The following are the recommendations for further research

1. The present study can be extended to different locations

2. Assessment can be made to a large number of samples

3. Necessary interventions can be made and implemented in order to overcome challenging behaviour

\section{CONCLUSION}

The present study showers a lime light for the teachers to determine the various behaviour issues faced by the children with autism. It also helps parents to understand the problem behaviours and to analyze the factors causing it. Also this study will direct the teachers and parents to design and implement the necessary intervention strategies in order to help the child to get rid of the problem behaviours.

\section{REFERENCES}

Aman, M. G., Tasse, M. J., Rojahn, J., \& Hammer, D. (1995). The Nisonger Child Behaviour Rating Form. Columbus, OH: Nisonger Centre for Mental Retardation and Developmental Disabilities, Ohio State University.

Aman, M. G., Tassé, M. J., Rojahn, J., \& Hammer, D. (1996). The Nisonger CBRF: A Child Behavior Rating Form for children with developmental disabilities. Research in Developmental Disabilities, 17, 41-57.

Tassé, M. J., Aman, M. G., Hammer, D., \& Rojahn, J. (1996). The Nisonger Child Behavior Rating Form: Age and gender effects and norms. Research in Developmental Disabilities, $17,59-75$.

Mangal, S.K. (2006): Statistics in Psychology and Education, 2nd ed. Prentice Hall of India Private Limited, New Delhi. 